\title{
Development and validation of zero and first-order derivative area under curve spectrophotometric methods for the determination of aripiprazole in bulk material and tablets
}

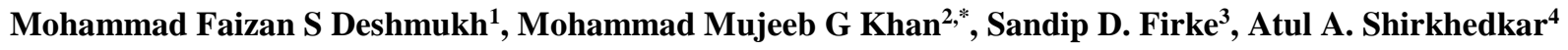 \\ ${ }^{1}$ Research Scholar, ${ }^{2,3}$ Assistant Professor, ${ }^{4}$ Professor, Dept. of Pharmaceutical Chemistry, R.C. Patel Institute of Pharmaceutical \\ Education and Research, Dist. Dhule, Maharashtra, India
}

*Corresponding Author:

Email: mujeebgulzar@gmail.com

\begin{abstract}
The proposed experiments explain simple, precise, specific and accurate UV spectrophotometry methods for the estimation of Aripiprazole in bulk and pharmaceutical formulation. Aripiprazole is a recent second generation atypical anti-psychotic drug used for the treatment of schizophrenia; four simple UV spectrophotometric methods were established for estimation of Aripiprazole, using double beam UV spectrophotometer (UV-2450, Shimadzu, Japan). Aripiprazole showed maximum absorbance ( $\lambda$ max) at $255 \mathrm{~nm}$ in methanolic $\mathrm{HCl}$ as a solvent. The calibration curve obeyed Beer-Lambert law in the concentration range of 5 -30 $\mu \mathrm{g} / \mathrm{mL}$. The \% recovery was found to be in the range of $98-100 \%$. Precision value less than 2 in terms of \% RSD indicates precise nature of developed methods. Validation of developed methods was carried out as per ICH guidelines. It was concluded that the results and statistical analysis amongst all four methods, AUC method is most simple, accurate, precise, and specific. All four methods can be used for routine analysis of Aripiprazole in bulk and pharmaceutical formulations.
\end{abstract}

Keywords: Aripiprazole, UV-Spectrophotometry, Derivatives Methods, Area Under Curve Method.

\section{Introduction}

Aripiprazole (ARP) is chemically 7-[4-[4-(2, 3dichlorophenyl) -1-piprazinyl] butoxy] -3, 4-dihydro$(1 H)$-quinolinone (Fig. 1). ${ }^{1}$ It is a recent second generation atypical anti-psychotic drug used for the treatment of schizophrenia and also used for the treatment of acute manic and mixed episodes associated with bipolar disorder. It has partial agonist activity at dopamine $\mathrm{D}_{2}$ and $\mathrm{D}_{3}$ receptors and serotonin $5-\mathrm{HT}_{1} \mathrm{~A}$ receptors, and antagonist activity at 5- $\mathrm{HT}_{2} \mathrm{~A}$ receptors. ${ }^{1,2}$

Literature survey revealed that many analytical methods for the determination of ARP. HPLC ${ }^{3-14}$ in pharmaceutical formulation and biological fluid has been reported. Liquid chromatography coupled with mass spectrometry, ${ }^{15-23}$ UPLC-MS ${ }^{24,25}$ and few spectrophotometric methods. ${ }^{26-30}$ However, till date no UV spectrophotometry method has been developed for the determination of ARP in bulk and pharmaceutical formulation using derivative spectroscopic techniques, AUC, and amplitude technique.

At the same time, our objective was to establish zero order, first order derivative using AUC technique and Amplitude technique. The current work emphasizes simple, sensitive and effective UV spectrophotometry method for determination of ARP in bulk material and in pharmaceutical formulation. Further, the developed method was validated according to ICH guidelines. ${ }^{32}$<smiles>O=C1CCc2ccc(OCCCCN3CCN(c4cccc(Cl)c4Cl)CC3)cc2N1</smiles>

Fig. 1: Chemical Structure of Aripiprazole

\section{Materials and Methods}

Chemicals: Pure ARP was obtained as a gift sample from Lupin Pharmaceutical Ltd., Mumbai, India. The marketed formulation (ARZU) 10mg was purchased from local market. Methanol and Hydrochloric acid were used as solvent for this experiment.

Instrumentation: A double beam UV-VIS spectrophotometer (Model- UV-2450, Shimadzu, Japan) equipped with $10 \mathrm{~mm}$ matched quartz cell and connected by computer operated in UV probe version 2.21 software was utilized in the current research work for all absorbance measurement. An electronic weighing balance (Model- AUX 120, Shimadzu, Japan) was used for weighing purpose.

Selection of Solvent: Solubility of ARP was checked in different solvents, it is partially soluble in methanoland freely soluble in $0.01 \mathrm{M}$ methanolic $\mathrm{HCl}$ after sonication for $18 \mathrm{~min}$. Hence $0.01 \mathrm{M}$ methanolic $\mathrm{HCl}$ was chosen as a solvent throughout the method development and validation process and there was no degradation effect occurs in this solvent.

Preparation of standard stock solution and determination of lambda ( $\lambda$ max): The Standard stock solution $(100 \mu \mathrm{g} / \mathrm{mL})$ prepared by accurately weighed $10 \mathrm{mg}$ of ARP, transferred in $100 \mathrm{~mL}$ volumetric flask 
and volume was made up with methanolic $\mathrm{HCl}$ upto the mark.

From the standard stock solution $1 \mathrm{~mL}$ of solution transferred to $10 \mathrm{~mL}$ volumetric flask. Further volume was made with same solvent upto the mark to obtained concentration (10 $\mu \mathrm{g} / \mathrm{mL})$. Resulting solution was scanned in the UV- region i.e. $400-200 \mathrm{~nm}$. In zero order spectrums, ARP showed absorbance maximum at 255 nm (Fig. 2).
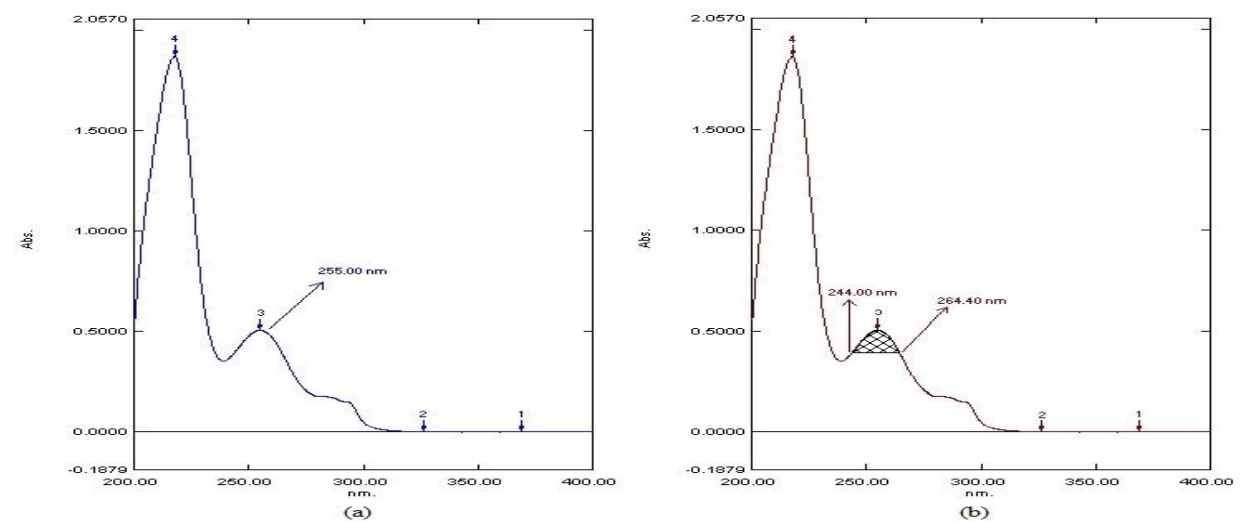

Fig 2: Zero Order Spectrum (a) and Area under Curve; (b) between selected wavelengths of Aripiprazole

Method A (Zero order derivative) and Method B (Zero order derivative-AUC): For method A and method B the standard stock solutions of ARP $(100 \mu \mathrm{g} / \mathrm{ml})$ were further diluted to prepared different sets of standard solution of ARP ranging from $(5-30 \mu \mathrm{g} / \mathrm{mL})$. For this aliquots of $0.5-3.0 \mathrm{~mL}$ of standard stock solution were separately pipette out and transferred to series of volumetric flask having capacity upto $10 \mathrm{~mL}$ then volume was made upto the mark with methanolic $\mathrm{HCl}$ solvent. For method A absorbance in zero order derivative spectrum was determined at $255 \mathrm{~nm}$ shown in (Fig. 2(a)).While for method B AUC in zero order spectrum was selected in between $244 \mathrm{~nm}$ and $264.40 \mathrm{~nm}$ shown in (Fig. 2(b)). The calibration curves of method A and method B were constructed by plotting concentration versus absorbance and AUC of zero order spectrum respectively, shown in (Fig. 3).

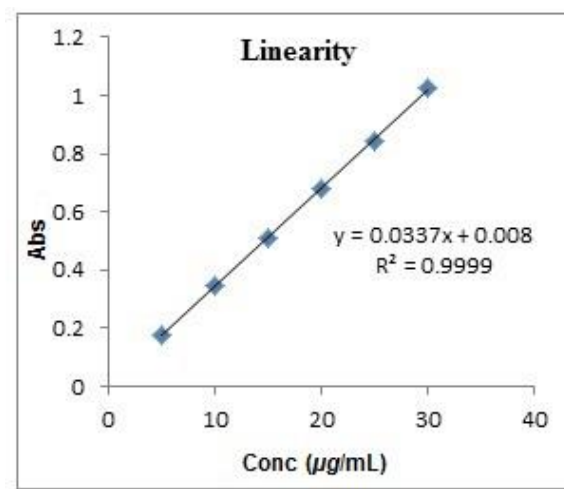

(a)

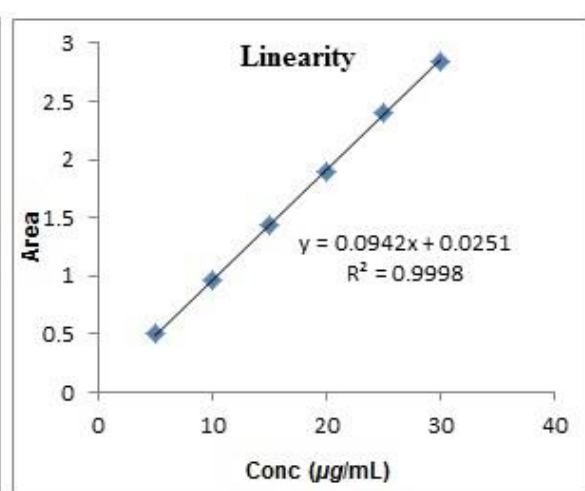

(b)

Fig. 3: Calibration Curve of Aripiprazole for Method A (a); and Method B (b)

Method C (First order derivative) and Method D (First order derivative-AUC): For method C and method D spectra of previous solution derivatized into first order spectra using UV probe 2.21 version software with delta 4 and scaling factor 10. In method C amplitude was determined at $266.40 \mathrm{~nm}$ shown in (Fig. 4(a)). While for method D AUC in first order spectrum was selected in between $259.80 \mathrm{~nm}$ and $273.40 \mathrm{~nm}$ shown in (Fig. 4(b)). The calibration curves of method $\mathrm{C}$ and $\mathrm{D}$ were constructed by plotting concentration versus amplitude and AUC of first order spectrum respectively, shown in (Fig. 5). 

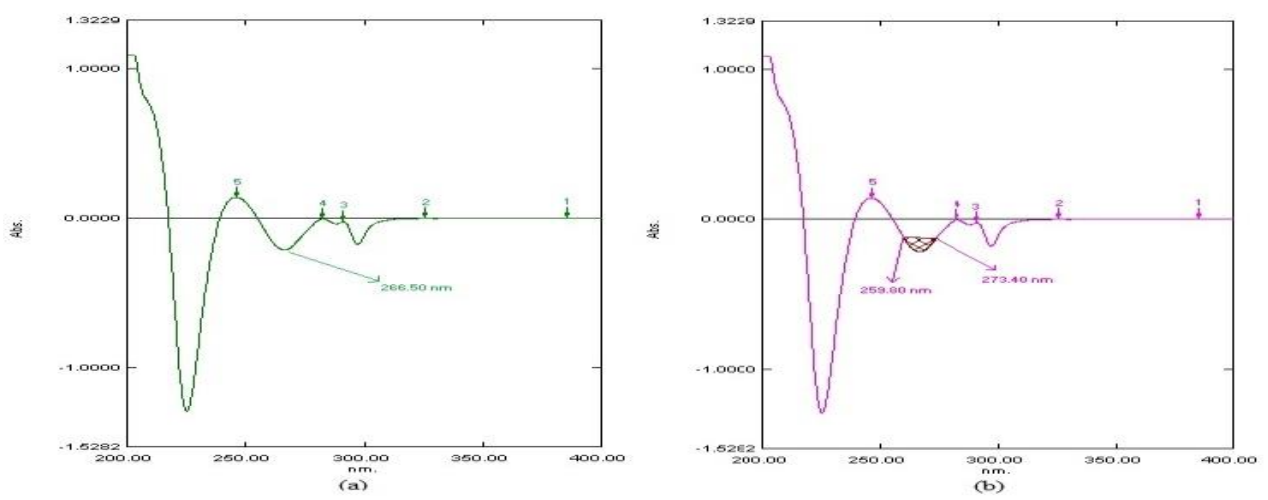

Fig. 4: First Order Derivative Spectrum (a) and Area Under Curve; (b) between selected wavelengths of Aripiprazole

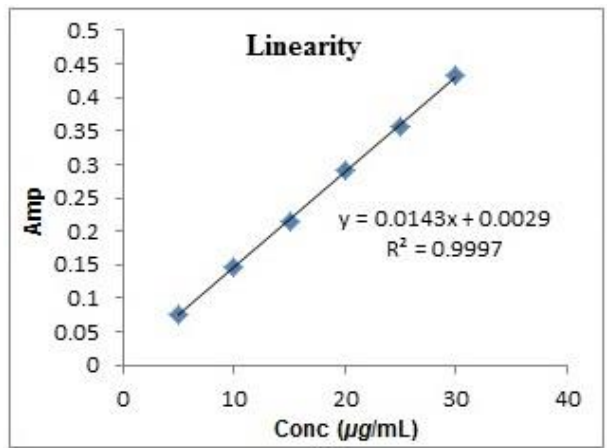

(a)

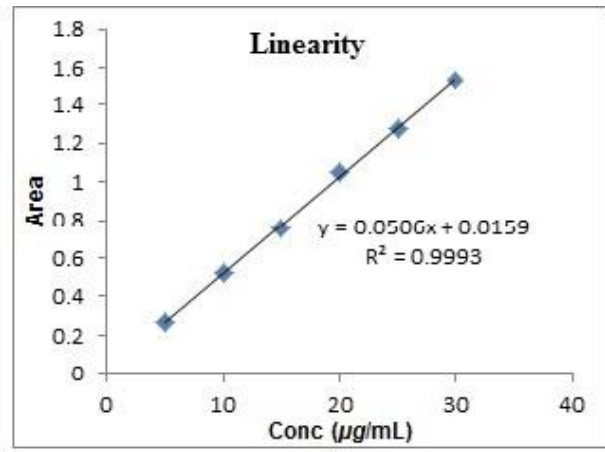

(b)

Fig. 5: Calibration Curve of Aripiprazole for Method C (a); and Method D (b)

Study of marketed formulation: For analysis of marketed formulation twenty tablets of ARP (ARZU having label claim $10 \mathrm{mg}$ ) were weighed and transferred to clean dry mortar then tablet grounded to fine powder by a pestle. Fine powder of tablet equivalent to $10 \mathrm{mg}$ of $\mathrm{ARP}$ was transferred to $100 \mathrm{~mL}$ volumetric flask containing $70 \mathrm{~mL}$ methanolic $\mathrm{HCl}$ and sonicated for $10 \mathrm{~min}$. After ultra-sonication volume was made upto the mark with methanolic $\mathrm{HCl}$ and filter through whatman filter paper (no. 41). From the filtrate sets of same concentration was separately transferred to $10 \mathrm{~mL}$ volumetric flask and volume was made upto the mark to get final concentration of $15 \mu \mathrm{g} / \mathrm{mL}$. The absorbance recorded and concentrations in the sample were determined from linearity equation.

\section{Validation of Method}

The propose method was validated with regard to various parameter i.e. linearity, precision, accuracy, limit of detection, limit of quantification and ruggedness according to $\mathrm{ICH}$ guide line. ${ }^{32}$

Linearity: The linearity of the "methods A, B, C, and D" was evaluated by analysis of six standard solutions of ARP of concentrations $05,10,15,20,25$, and 30 $\mu \mathrm{g} / \mathrm{mL}$. The calibration curve was obeyed in the concentration of range $5-30 \mu \mathrm{g} / \mathrm{mL}$ and the graph was plotted between concentrations versus absorbance, amplitude and AUC.
Accuracy: The accuracy of all methods was evaluated by measurement of recovery. To the pre-analyzed sample solutions $(10 \mu \mathrm{g} / \mathrm{mL}$ in all method), known amounts of stock standard solutions were added at different levels, that is, $80 \%, 100 \%$, and $120 \%$. The solutions were reanalyzed through the developed methods. The experiments were repeated for three times at each level for method.

Precision: Precision of the methods was studied in the form of intra-day and inter-day variations. For "all methods," precision was found out by analyzing the 10 , 15 , and $20 \mu \mathrm{g} / \mathrm{mL}$ of ARP solutions separately for intraday and inter-day variations.

Sensitivity: For sensitivity measurements, solution of ARP analyzed by developed methods and estimated in terms of limit of detection (LOD) and limit of quantification (LOQ) which were calculated using formulae " $\mathrm{LOQ}=10 \times \mathrm{N} / \mathrm{B}$ " and " $\mathrm{LOD}=3.3 \times \mathrm{N} / \mathrm{B}$," where " $\mathrm{N}$ " is average standard deviation of the amplitudes or peak areas of the ARP $(n=3)$, taken as a measure of noise, and " $\mathrm{B}$ " is the slope related to calibration curve.

Repeatability: In "all methods" repeatability was estimated by analyzing of $15 \mu \mathrm{g} / \mathrm{mL}$ solution of ARP for six times.

Ruggedness: For "all methods" ruggedness of developed methods was determined by analyzing of 15 
$\mu \mathrm{g} / \mathrm{mL}$ solution of ARP by two different analysts using similar operational and environmental conditions.
Result and Discussion

Method validation: ARP was validated with respect to the following parameters linearity, accuracy, precision, sensitivity, LOD, LOQ, and ruggedness. The results were found to be acceptable as per guidelines. The data of regression analysis shown in (Table 1).

Table 1: Optical Characteristics of Aripiprazole

\begin{tabular}{|l|c|c|c|c|}
\hline Parameters & Method A & Method B & Method C & Method D \\
\hline $\begin{array}{l}\text { Beer-Lambert's } \\
\text { range }(\mu \mathrm{g} / \mathrm{mL})\end{array}$ & $05-30$ & $05-30$ & $05-30$ & $05-30$ \\
\hline Lambda Max $(\mathrm{nm})$ & 255 & $244.00-264.40$ & 266.50 & $259.80-273.40$ \\
\hline Slope & 0.0337 & 0.0942 & 0.0143 & 0.0506 \\
\hline Intercept & 0.008 & 0.0251 & 0.0029 & 0.0156 \\
\hline $\begin{array}{l}\text { Correlation } \\
\text { coefficient }\end{array}$ & 0.9999 & 0.9998 & 0.9997 & 0.9993 \\
\hline
\end{tabular}

Linearity: From the linear regression data it was cleared that for "methods A, B, C, and D" calibration curves shown in (Fig. $3 \& 5$ ) linear relationship over the concentration range of $5-30 \mu \mathrm{g} / \mathrm{mL}$ for ARP shown in (Table 1). Accuracy: For determination of accuracy of the developed methods, pure drug solution was added in pre-tested sample solution at three different concentration levels; $80 \%, 100 \%, 120 \%$. The results were depicted in (Table 2). The $\%$ Recovery values indicate that the accuracy of the methods was found to be satisfactory.

Table 2: Accuracy studies

\begin{tabular}{|c|c|c|c|c|c|c|}
\hline Drug & Methods & $\begin{array}{c}\text { Initial } \\
\text { amount } \\
{[\mu \mathrm{g} / \mathrm{mL}]}\end{array}$ & $\begin{array}{c}\text { Amount } \\
\text { added } \\
{[\mu \mathrm{g} / \mathrm{mL}]}\end{array}$ & $\begin{array}{c}\text { Amount } \\
\text { recovered } \\
{[\mu \mathrm{g} / \mathrm{mL} \text {, }} \\
\mathbf{n}=3]\end{array}$ & $\begin{array}{c}\% \\
\text { Recovered }\end{array}$ & $\begin{array}{c}\% \\
\text { RSD }\end{array}$ \\
\hline \multirow{12}{*}{ Aripiprazole } & A & 10 & 8 & 17.92 & 98.97 & 0.62 \\
\hline & & 10 & 10 & 19.98 & 99.76 & 0.67 \\
\hline & & 10 & 12 & 21.96 & 99.64 & 0.30 \\
\hline & $\mathrm{B}$ & 10 & 8 & 17.94 & 99.26 & 0.43 \\
\hline & & 10 & 10 & 19.89 & 98.92 & 0.18 \\
\hline & & 10 & 12 & 21.95 & 99.59 & 0.49 \\
\hline & $\mathrm{C}$ & 10 & 8 & 17.98 & 99.74 & 0.92 \\
\hline & & 10 & 10 & 20.03 & 100.30 & 0.81 \\
\hline & & 10 & 12 & 21.88 & 99.03 & 0.66 \\
\hline & $\mathrm{D}$ & 10 & 8 & 17.99 & 99.88 & 1.24 \\
\hline & & 10 & 10 & 20.04 & 100.40 & 0.17 \\
\hline & & 10 & 12 & 22.01 & 100.07 & 0.39 \\
\hline
\end{tabular}

\section{n- number of determinations}

\section{Precision}

Intra-day: For intraday precision studies three replicates of three different concentration $10,15,20 \mu \mathrm{g} / \mathrm{mL}$ was analyzed at different time in same day. The \% RSD and data demonstrate in (Table 3).

Table 3: Precision studies

\begin{tabular}{|c|c|c|c|c|c|c|}
\hline Drug & Methods & $\begin{array}{c}\text { Concentration } \\
{[\boldsymbol{\mu g} / \mathbf{m L}]}\end{array}$ & $\begin{array}{c}\text { Intra-day } \\
{[\mathbf{n}=\mathbf{3}]}\end{array}$ & $\begin{array}{c}\text { \% } \\
\mathbf{R S D}\end{array}$ & $\begin{array}{c}\text { Inter-day } \\
{[\mathbf{n}=\mathbf{3}]}\end{array}$ & $\begin{array}{c}\text { \% } \\
\mathbf{R S D}\end{array}$ \\
\hline \multirow{4}{*}{ Aripiprazole } & & 10 & 9.92 & 0.88 & 10.01 & 0.44 \\
\cline { 2 - 7 } & $\mathrm{A}$ & 15 & 14.91 & 0.61 & 14.92 & 0.59 \\
\cline { 2 - 7 } & & 20 & 20.05 & 0.34 & 20.03 & 0.10 \\
\cline { 2 - 7 } & & 10 & 9.91 & 0.34 & 10.05 & 0.17 \\
\cline { 2 - 7 } & $\mathrm{B}$ & 15 & 14.93 & 0.62 & 14.95 & 0.20 \\
\cline { 2 - 7 } & & 20 & 19.97 & 0.06 & 20.18 & 0.48 \\
\cline { 2 - 7 } & & & & & & \\
\hline
\end{tabular}




\begin{tabular}{|c|c|c|c|c|c|c|}
\hline \multirow{7}{*}{} & & 10 & 9.89 & 0.43 & 10.01 & 0.43 \\
\cline { 2 - 7 } & $\mathrm{C}$ & 15 & 14.90 & 0.55 & 14.86 & 0.75 \\
\cline { 2 - 7 } & & 20 & 20.19 & 0.19 & 20.20 & 0.21 \\
\cline { 2 - 7 } & & 10 & 10.02 & 0.19 & 10.10 & 0.45 \\
\cline { 2 - 7 } & $\mathrm{D}$ & 15 & 14.75 & 0.14 & 14.80 & 0.12 \\
\cline { 2 - 7 } & & 20 & 20.18 & 0.21 & 20.10 & 0.19 \\
\hline
\end{tabular}

n- number of determinations

Inter-day: For inter-day precision three replicates of three different concentrations $10,15,20 \mu \mathrm{g} / \mathrm{mL}$ was analyzed in different day subsequently. The \% RSD and data demonstrate in (Table 3).

Sensitivity: The LOD and LOQ for ARP in "method A" were found to be $0.26 \mu \mathrm{g}$ and $0.77 \mu \mathrm{g}$, in "method B" 0.37 $\mu \mathrm{g}$ and $1.11 \mu \mathrm{g}$, "method C" $0.24 \mu \mathrm{g}$ and $0.72 \mu \mathrm{g}$, while "method D" $0.29 \mu \mathrm{g}$ and $0.87 \mu \mathrm{g}$.

Repeatability: The results of repeatability in terms of \% RSD for "methods A, B, C, and D," were less than 2 indicates precise nature of developed methods. Results are shown in (Table 4).

Table 4: Repeatability studies

\begin{tabular}{|c|c|c|c|c|c|c|}
\hline Drug & Methods & $\begin{array}{c}\text { Amount } \\
\text { taken } \\
{[\boldsymbol{\mu g} / \mathbf{m L} \mathbf{L}]}\end{array}$ & $\begin{array}{c}\text { Amount } \\
\text { found } \\
{[\mathbf{\mu g} / \mathbf{m L}]}\end{array}$ & $\begin{array}{c}\text { \% Amount } \\
\text { found } \\
{[\mathbf{n = 6}]}\end{array}$ & Mean $\mathbf{\text { SD }}$ & $\begin{array}{c}\text { \% } \\
\text { RSD }\end{array}$ \\
\hline & $\mathrm{A}$ & 15 & 15.03 & 100.92 & $100.92 \pm 0.59$ & 0.59 \\
\hline & $\mathrm{B}$ & 15 & 15.28 & 101.90 & $101.90 \pm 0.60$ & 0.59 \\
\hline Aripiprazole & $\mathrm{C}$ & 15 & 15.01 & 100.05 & $100.05 \pm 0.86$ & 0.86 \\
\hline & $\mathrm{D}$ & 15 & 14.97 & 99.80 & $99.80 \pm 1.19$ & 1.19 \\
\hline
\end{tabular}

n- number of determinations

Ruggedness: The results of ruggedness were in acceptable range that is \% RSD values $<2$ for all the developed methods as given in (Table 5). The results prove no statistical differences between different analyst using same operational and environmental condition. Hence it signifies that the developed methods are rugged in nature.

Table 5: Ruggedness studies

\begin{tabular}{|c|c|c|c|c|c|}
\hline & & \multicolumn{2}{|c|}{ Analyst I } & \multicolumn{2}{c|}{ Analyst II } \\
\hline \multirow{2}{*}{ Drug } & Methods & $\begin{array}{c}\text { \% Amount } \\
\text { found } \pm \text { SD } \\
{[\mathbf{n}=3]}\end{array}$ & \% RSD & $\begin{array}{c}\text { \% Amount } \\
\text { found } \pm \text { SD } \\
{[\mathbf{n}=\mathbf{3}]}\end{array}$ & \% RSD \\
\hline \multirow{4}{*}{ Aripiprazole } & $\mathrm{A}$ & $98.84 \pm 0.66$ & 0.66 & $101.50 \pm 1.90$ & 1.87 \\
\cline { 2 - 6 } & $\mathrm{B}$ & $99.99 \pm 0.79$ & 0.79 & $100.33 \pm 0.97$ & 0.97 \\
\cline { 2 - 6 } & $\mathrm{C}$ & $100.33 \pm 0.16$ & 1.06 & $98.55 \pm 0.88$ & 0.90 \\
\cline { 2 - 6 } & $\mathrm{D}$ & $99.13 \pm 0.79$ & 0.80 & $99.29 \pm 0.69$ & 0.69 \\
\hline
\end{tabular}

n- number of determinations

Analysis of Tablet Formulation: From ARP tablet formulation amount of ARP estimated by using methods $\mathrm{A}, \mathrm{B}, \mathrm{C}$ and $\mathrm{D}$ were found to be $99.55 \%$, $100.08 \%, 99.04 \%$, and $99.27 \%$, respectively. The \% amount found from tablet formulation shows that there was no interference from excipients present in tablet formulation.

\section{Conclusion}

All methods were established for quantitative analysis of ARP in bulk and tablet formulation by using derivative spectroscopic technique and AUC technique of UV-spectrophotometry. The results and statistical analysis show that amongst all methods, AUC method is most simple, accurate, precise, and specific. Therefore, these all methods can be used for routine analysis of ARP in bulk and pharmaceutical formulation.

\section{Acknowledgement}

Authors are thankful to Dr. S. J. Surana, Principal R. C. Patel Institute of Pharmaceutical Education and Research, Shirpur, Dist: Dhule (MS) for providing necessary laboratory facility.

\section{Disclosure of Interest}

The authors have none to declare

\section{References}

1. The Merck Index. (2006).an encyclopedia of chemicals, drugs, and biological. $14^{\text {th }}$ ed, Merk\& Co., Inc, Whitehouse Station, NJ, USA, P.129. 
2. Government of India. (2014). Ministry of health and family welfare. Indian Pharmacopoeia Vol. I \& II. The Indian Pharmacopoeia Commission, Ghaziabad, 1-1081.

3. Mauri, M. C., Paletta, S., Maffini, M., Colasanti, A., Dragogna, F., et al. (2014). Clinical pharmacology of atypical antipsychotics: an update. EXCLI journal, 13, 1178-9.

4. Thakkar, R. S., Saravaia, H. T., Ambasana, M. A., Kaila, H. O., Shah, A. K. (2011). A chromatographic determination of aripiprazole using HPLC and UPLC: A comparative validation study. Indian J Pharm Sci, 73(4), 439-43.

5. Ahmed N., Shaikh O., Barrawaz A., Khan S., Zaheer Z. (2017). Development and Validation of Rapid HPLC Method for Determination of Aripiprazole in Bulk Drug and Pharmaceutical Formulation. Journal of Innovations in Pharmaceutical and Biological Sciences, 4(3), 15-9.

6. Ravindra, N., Singhvi, I., Kumara, Swamy, G. (2014). New RPHPLC method for the estimation of aripiprazole in bulk and in pharmaceutical dosage forms. Indo. Am. J. Pharm. Res, 4(4), 1842-9.

7. Nagasarapu, M. R., Dannana, G. (2017). New stability indicating high performance liquid chromatography method for the estimation of aripiprazole in bulk and their formulations.Indian Journal of Drugs, 5(3),116-23.

8. Prasenjit, M., Shobha, S. R., Alekhya, K. (2013). A new stability indicating validated method for the determination of aripiprazole in bulk and tablet dosage form using RP-HPLC. Int J Pharm Pharm Sci, 5(4), 6605.

9. Kumari M. V., Eswaramma P., Kumar A. E., Rao K. V., Narendra M., et al. (2016). Analytical method validation of aripiprazole in pharmaceutical dosage form by RPHPLC.World Journal of Pharmacy and Pharmaceutical Sciences, 5(6),1168-79.

10. Narayana, M. B., Chandrasekhar, K. B., Rao, B. M. (2014). A validated specific stability-indicating RPHPLC method for aripiprazole and its related substances. J Chem Pharm Res, 91(3), 4426-35.

11. Vijayabharathi, K., Shaik, M., Chandra, Sekhar, K., B. (2017). A novel stability inducating reverse phase high performance liquid chromatography method development and validation for the quantification of aripiprazole in pure and its pharmaceutical formulation. Asian J Pharm Clin Re, 10(5), 379-82.

12. Marszalek, D., Goldnik, A., Pawinski, T., Malek, G., Somogi, A., et al. (2017). Simultaneous assay of aripiprazole and its active metabolite in serum by HPLC.Acta Pol Pharm, 74(2), 405-11.

13. Shimokawa, Y., Akiyama, H., Kashiyama, E., Koga, T., Miyamoto, G. (2005).High performance liquid chromatographic methods for the determination of aripiprazole with ultraviolet detection in rat plasma and brain: application to the pharmacokinetic study. $\mathrm{J}$ Chromatogr B, 821, 8-14.

14. Musenga, A., Saracino, M. A., Spinelli, D., Rizzato, E., Boncompagni, G., et al. (2008). Analysis of the recent antipsychotic aripiprazole in human plasma by capillary electrophoresis and high-performance liquid chromatography with diode array detection. Anal Chim Acta, 612(2), 204-11.

15. Christine, M., Salem, H., Amer, S. M., Nebsen, M. (2017). Validated HPLC method for simultaneous determination of aripiprazole and co-administered clonazepam in spiked human plasma. J. Pharm. Appl. Chem, 3(1),57-61.

16. Caloro, M., Lionetto, L., Cuomo, I., Simonetti, A., Pucci, D., et al. (2012). An improved simple LC-MS/MS method for the measurement of serum aripiprazole and its major metabolite. J Pharm Biomed Anal, 62, 135-9.

17. Kubo, M., Mizooku, Y., Hirao, Y., Osumi, T. (2005). Development and validation of an LC-MS/MS method for the quantitative determination of aripiprazole and its main metabolite, OPC-14857, in human plasma. J Chromatogr B, 822(1-2), 294-9.

18. Ambavaram, V. B., Nandigam, V., Vemula, M., Kalluru, G. R., Gajulapalle, M. (2013). Liquid chromatographytandem mass spectrometry method for simultaneous quantification of urapidil and aripiprazole in human plasma and its application to human pharmacokinetic study. Biomed Chromatogr, 27(7), 916-23.

19. Patel, D. S., Sharma, N., Patel, M. C., Patel, B. N., Shrivastav, P. S., et al. (2014). Development and validation of a rapid and sensitive LC-MS/MS method for the determination of aripiprazole in human plasma: Application to a bioequivalence study.ActaChromatogr, 26(2), 203-227.

20. Makwana, K. U., Dhamecha, R. V., Kosalge, S. (2011). A rugged and economic method for the estimation of aripiprazole in human serum by LCMS/MS detection for clinical trials.Int J Pharm Pharm Sci, 3(5),121-4.

21. Song, M., Xu, X., Hang, T., Wen, A., Yang, L. (2009). Development of an LC-MS/MS method for the simultaneous quantification of aripiprazole and dehydroaripiprazole in human plasma. Anal. Biochem, 385(2), 270-7.

22. Zuo, X. C., Wang, F., Xu, P., Zhu, R. H. (2006). LCESI-MS for rapid and sensitive determination of aripiprazole in human plasma. Chromatographia, 64(7-8), 387-91.

23. Ravinder, S., Bapuji, A. T., Mukkanti, K., Raju, D. R., Ravikiran, H. L., Reddy, D. C. (2012). Development and validation of an LC-ESI-MS method for quantitative determination of aripiprazole in human plasma and an application to pharmacokinetic study.J ChromatogrSci, 50(10), 893-901.

24. Lin, S. N., Lamm, L., Newton, T. F., Reid, M. S., Moody, D. E., et al. (2009). A liquid chromatography-electrospray ionization-tandem mass spectrometry method for quantitation of aripiprazole in human plasma. J Anal Toxicol, 33(5), 237-42.

25. Liang, F., Terry, A. V., Bartlett, M. G. (2012). Determination of aripiprazole in rat plasma and brain using ultra-performance liquid chromatography/electrospray ionization tandem mass spectrometry. Biomed Chromatogr,26(11),1325-32.

26. Patel, D. P., Sharma, P., Sanyal, M., Shrivastav, P. S. (2013). SPE-UPLC-MS/MS method for sensitive and rapid determination of aripiprazole in human plasma to support a bioequivalence study. J Chromatogr B, 925, 205.

27. Sandeep, K., Induri, M., Sudhakar, M. (2013). Validated spectrophotometric quantification of aripiprazole in pharmaceutical formulations by using multivariate technique. Adv Pharm Bull, 3(2), 469-72.

28. Younes, K. M. (2014). Stability indicating spectrophotometric and tlc-densitometric methods for the determination of aripiprazole in bulk and dosage form. Int J Pharm PharmSci, 6(4), 542-8.

29. Sri, Ramya.Y. N., Vijayalakshmi, R., Dhanaraju, M. D. (2015). Spectrophotometric determination of aripiprazole and tapentadol using chloranilic acid reagent.Int J Pharm Sci Res, 6(5),2052-5.

30. Kalaichelvi, R., Thangabalan, B., Rao, D. S., Jayachandran, E. (2009). UV spectrophotometric 
determination of aripiprazole in bulk and pharmaceutical formulation. Journal of Chemistry,6(S1),S87-90.

31. Jain, R., Kashaw, S. K., Jain, R., Mishra, P., Kohli, D. V. (2011). Visible spectrophotometric method for the determination of aripiprazole in tablets. Indian J Pharm Sci, 73(1), 74-6.

32. ICH Harmonized Tripartite Guideline, Q2 (R1): Validation of Analytical Procedures: Text and Methodology, International Conference on Harmonization, Geneva, Switzerland, 2005. 